\title{
Analysis of accidents and injuries on motorcycles in Mexico
}

\author{
Luis David Berrones-Sanz
}

College of Science and Technology, Universidad Autónoma de la Ciudad de México, Mexico City, Mexico

\begin{abstract}
Objective: To analyze the type of injuries and the characteristics and geographical distribution of road accidents where motorcycles were involved in Mexico. Methods: A descriptive analysis of second-hand information sources was conducted, including the number of accidents $(N=41,881)$, total number of injured people $(N=13,916)$ and medical expenses $(N=9,111)$ associated to motorcycle accidents during 2014. Results: Motorcycles represent $13.14 \%$ of the total number of deaths in road accidents in Mexico, and the Southeast region of Mexico registers the highest proportion of fatal injuries. Of the total number of motorcycles, $1.84 \%$ (95\% confidence interval [Cl]: 1.83-1.86) were involved in a collision. 3.64 (95\% Cl: 3.39-3.89) people died and 105.5 (95\% Cl: 104.1-106.8) were injured in every 10,000. Out of the total number of injuries, $76.6 \%$ were male and $53.74 \%$ were women. $55.1 \%$ of deaths were caused by intracranial trauma. Only $16.6 \%$ wore a helmet at the time of the accident, and those not wearing a helmet had a 2.11 (odds ratio [OR]: 2.1; Cl 95\%: 1.8-2.4) higher chance of head injury. Regarding the severity of the crash, those occurred in suburban areas (OR: 6.58; CI 95\%: 5.69-7.60), in unpaved surfaces (OR: 4.13; Cl 95\%: 3.04-5.61), after low alcohol consumption (OR: 1.89; Cl 95\%: 1.46-2.44), at night (OR: 2.24; Cl 95\%: 1.95-2.57) and on weekends (OR: 1.65; $\mathrm{Cl} 95 \%$ : 1.44-1.90), had the highest chance of turning into a fatal accident. Conclusions: In spite of the progress made in terms of road safety, motorcycle accidents are still increasing, and the use of a helmet is still proportionally low. More information on these groups and risk factors needs to be available so people are better informed. Also, regulations need improvements regarding the use of security equipment like helmets in order to reduce injuries and fatal accidents.
\end{abstract}

KEY WORDS: Road accidents. Helmet. Motorcycle. Road safety. Injuries.

\section{Introduction}

Motorcycles are attractive for several reasons: for amusement, for prestige, for costs associated with the vehicle and fuel efficiency, low polluting emissions or fast travels in increasingly congested cities. However, motorcycle users are at particularly high risk of collision injuries ${ }^{1-3}$, and motorcycle riding is therefore considered to be a dangerous activity ${ }^{4}$. Although in other countries motorcycle accidents have been drastically reduced $^{5}$, in Mexico, injuries are a problem that is increasing together with the number of vehicles.

To decrease damages, efforts are focused on reducing head injuries through traffic regulations, which mandate the use of safety helmets; however, social psychology models, where people's beliefs and behaviors have to be used to predict their behavior and influence on safe driving, are set aside. To create injure-reduction programs for motorcyclists, it is essential for their characteristics and different social, economic, cultural, spatial and temporal variables to be known. Thus, in this work, an analysis of motorcycle accidents is carried out with the purpose to identify subgroups and characteristics of motorcyclists at particularly high risk of accidents. Initially, the behavior of the installed base of vehicles and the geographic distribution of accidents will be considered and the databases on accidents, hospital discharges and injured motorcyclists will subsequently be analyzed. We

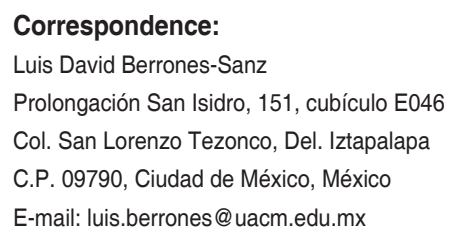

Date of reception: 09-08-2016

Date of acceptance: $14-07-2017$

DOI://dx.doi.org/10.24875/GMM.M18000053
Gac Med Mex. 2017;153:596-604

Contents available at PubMed www.gacetamedicademexico.com 
consider that this analysis will allow for key elements to be identified in order to establish specific actions contributing to the assessment and follow-up of public policies regarding the use of motorcycles.

\section{Method}

A secondary analysis of the Registry of Circulating Motor Vehicles and Road Traffic Accidents of the National Institute of Statistics and Geography (INEGI Instituto Nacional de Estadística y Geografía) $)^{6,7}$, together with the General Directorate of Health Information database of injured subjects and hospital discharges, was carried out ${ }^{8}$.

The study population included total motorcycle accidents $(N=41,881)$, total injured subjects $(N=13,916)$ and hospital discharges in the year 2014. The population, the number of registered motorcycles and the number of accidents occurred at each state of the nation were initially used in order to carry out a geographical analysis and to determine both motorcycle density and the distribution of accidents throughout the country. Subsequently, all available variables were used: anatomical region of injury, time reference, accident characteristics, geographic reference and characteristics of the responsible driver and of the injured, among others. With this, a statistical analysis that included the description, categorization and association of variables was performed using the proportion differences and chi-square tests. The odds ratio (OR) with its $95 \%$ confidence interval $(\mathrm{Cl})$ was calculated in associated variables, and it was mainly used for the comparison of the type of accident (fatal, non-fatal) or injuries in the anatomic region of the head.

By the year of 2014, in Mexico there were little over 38 million registered circulating motor vehicles reported, out of which $67.18 \%$ corresponded to automobiles, $0.91 \%$ to passenger buses, $25.94 \%$ to freight trucks and vans and $5.97 \%$ to motorcycles, with the latter having the highest proportion in history. Figure 1 illustrates the behavior in the number of vehicles for automobiles and motorcycles since the year 1980, and how motorcycles have had a highly accelerated growth over the last decade. Thus, from the year 2004 to the year 2014 , the number of motorcycles in the country increased 3.38-fold, with a mean annual growth rate of $15.92 \%$. However, the country does not behave homogeneously: for example, in motorcycle number absolute growth in all 32 states of the country, it draws the attention that only the state of Coahuila had a decreasing behavior (-38.18\%) in the same decade and, of the rest, three states significantly increased their number of motorcycles: Oaxaca, with $751.47 \%$; Tlaxcala, with $984.98 \%$; and the State of Mexico, with a highly superior than average growth of $4929.01 \%$. However, the State of Mexico is the most populated state of the country and only 1.46 motorcycles are registered for every 100 inhabitants, and Quintana Roo with $8.99 \%$, Campeche with $7.83 \%$ and Yucatán with $5.82 \%$ are therefore the states with more motorcyclists per

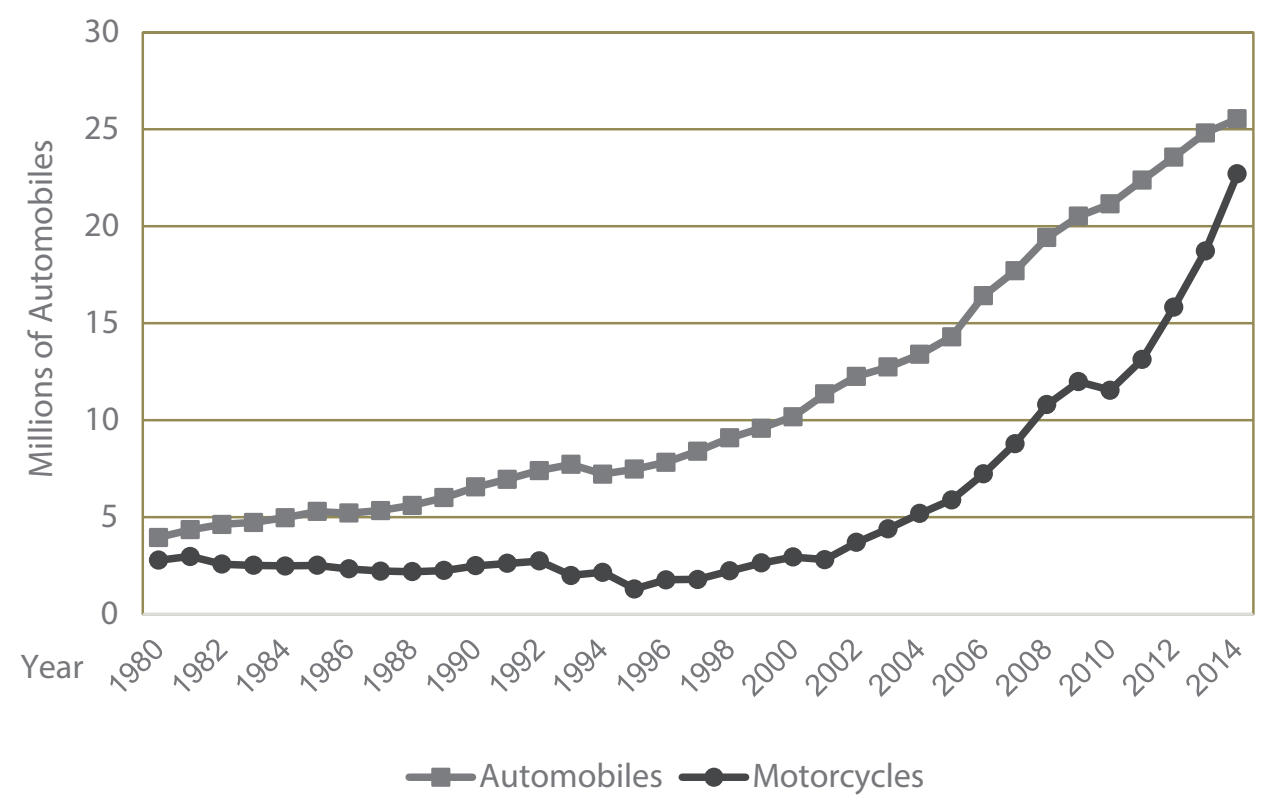

Figure 1. Evolution of the installed base of vehicles in Mexico. 
inhabitant. In turn, Coahuila, with $0.09 \%$, remains with the lowest proportion of motorcycles per inhabitant.

For the year 2014, INEGI recorded 41,881 motorcycle accidents in the national territory, and therefore there were 34.98 accidents (95\% Cl: 34.6-35.3) per 100,000 population. As figure 2 shows, accidents have a growing trend and, in the last decade, there was an absolute growth of $96 \%$, at an average rate of $6.95 \%$ per year in the number of total accidents, and a $10.88 \%$ growth for fatal accidents. The increase in the installed base of vehicles as regards motorcycles is positively correlated with the number of accidents $(R=0.93 ; p<0.001)$ and, unfortunately, with the number of deaths, the percentage of which went from nearly 2.5 to 6.9 (95\% Cl: 6.4-7.4) deaths per million population. In addition, the proportions are more critical when accidents are related to the number of vehicles (total accidents/total registered motorcycles), since in $2014,1.84 \%$ of motorcycles $(95 \% \mathrm{Cl}$ : $1.83-$ 1.86) were involved in a collision, 3.64 persons died (95\% Cl: 3.39-3.89) and there were 105.5 injured (95\% Cl: 104.1-106.8) for every 10,000 registered motorcycles.

Figure 3 shows a map of total number of accidents per state; the pie charts show the proportion of collisions, and the dots show the number of registered motorcycles (installed base of vehicles) at each state.

Southeast of the country (Campeche, Quintana Roo and Yucatán), with the highest rate of motorcycles per inhabitant, is consistent with the higher number of accidents (108.71, 155.37 and 124.74 per 100,000 population, respectively), with Quintana Roo being the state with the highest mortality rate (2.9 deaths per 100,000 population), followed by Sinaloa $(2.4 / 100,000)$ and Aguascalientes $(1.8 / 100,000)$. Interestingly, in the north of the country, despite the low motorization rate and accidents per inhabitant being at intermediate values, accidents per number of registered motorcycles show an increase. Thus, the pie charts (Fig. 3) show, for example, that $51.3 \%$ of registered motorcycles in Coahuila, $14.3 \%$ in Sonora and $10.8 \%$ in Chihuahua suffered accidents. Conversely, the State of Mexico, in spite of the atypical value it has recorded in the motorcycle number increase, appears with the lowest number of collisions at all indicators: 4.8 collisions per 100,000 population and $0.3 \%$ of accidents in registered motorcycles.

The male gender is predominant in motorcycle collision injured people in Mexico with $76.6 \%$, out of which $49.3 \%$ are younger than 25 years and $60.1 \%$ have a level of education of 9 years or less. Gender accounts for the main difference between the analyzed characteristics.

With regard to the type of user, $30.2 \%$ of the injured subjects are not drivers, but passengers, and in this category females are the most affected; this category comprises $53.74 \%$ of total female gender, the highest percentage for this gender.

Ion the case of temporality, the month of August had the highest number of collisions $(9.73 \%)$ and January had the lowest $(6.09 \%)$, mainly on weekends

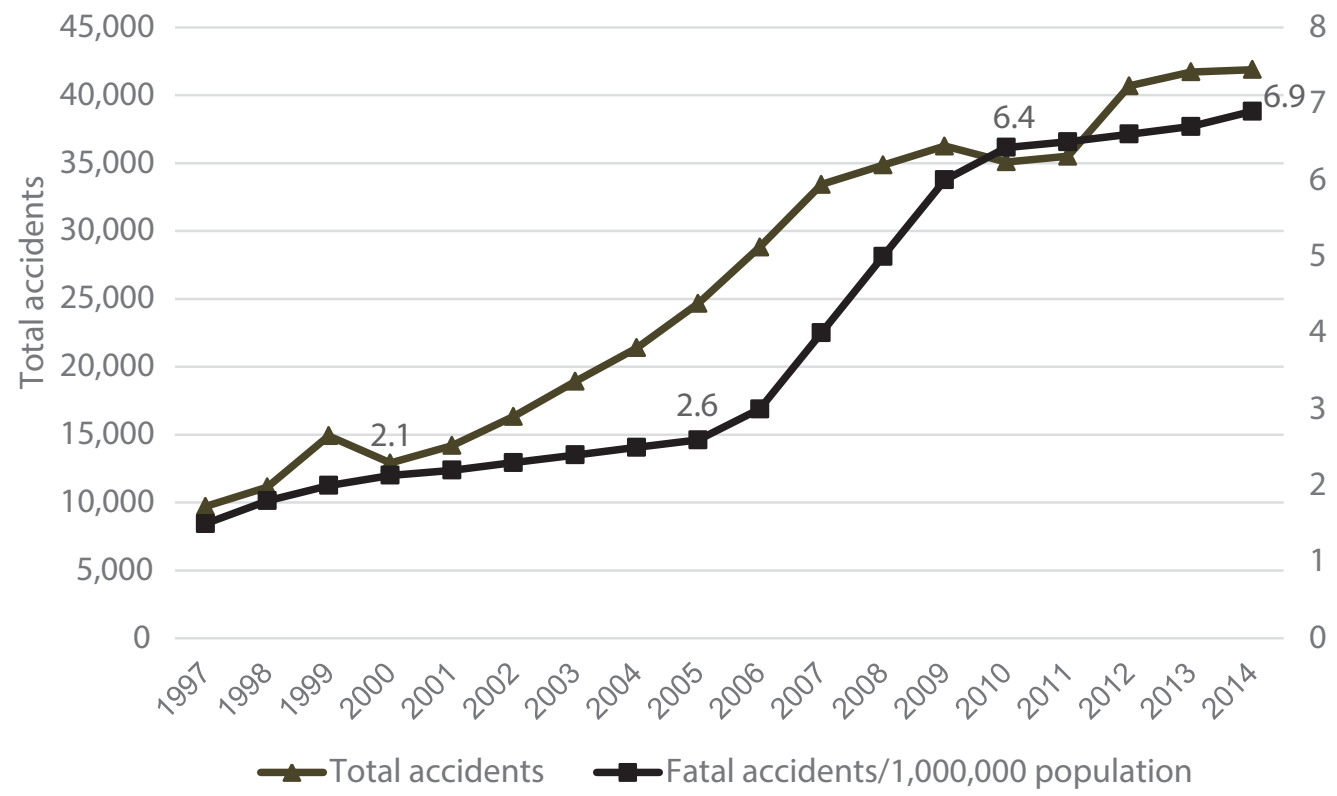

Figure 2. Historical record of motorcycle collisions in Mexico. 


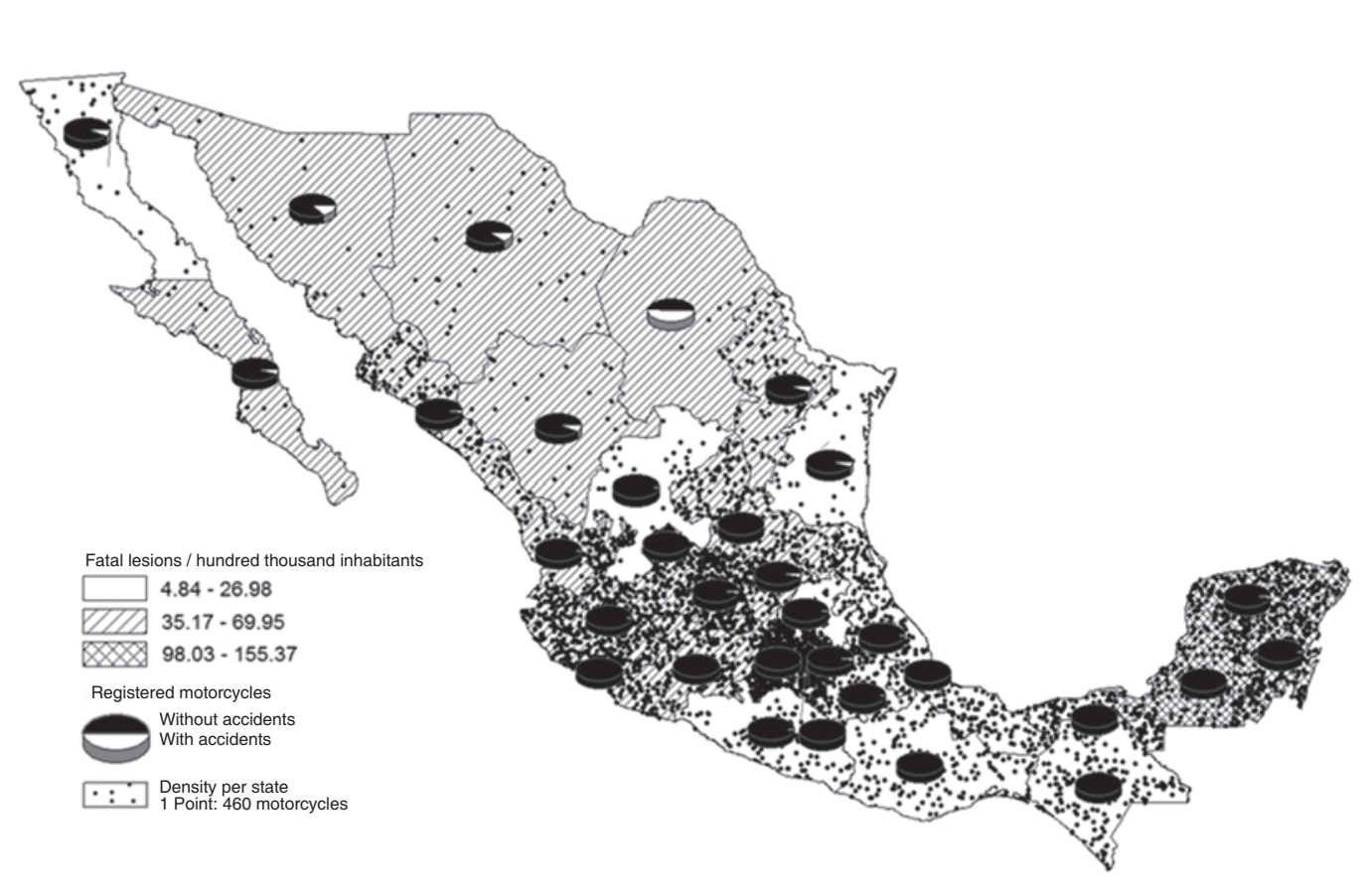

Figure 3. Map of injuries, accidents and registered motorcycles. The density of registered motorcycles shows the installed base of vehicles corresponding to each state.

(Saturdays $15.8 \%$ and Sundays $12.7 \%$ ). Other results, such as the type of accident, the road surface or the area where the collision occurred, which indicate that $98.48 \%$ of accidents occur in paved zones and $91.76 \%$ in urban areas, are shown in table 1.

This way, when the type of accident (fatal or non-fatal) was related to some variables, higher risk of dying was found in suburban areas (OR: 6.58; 95\% Cl: 5.697.60), unpaved road surfaces (OR. 4.13; 95\% Cl: 3.045.61), nighttime hours (OR: 2.24; $95 \% \mathrm{Cl}: 1.95-2.57$ ) and weekends (OR: 1.65; 95\% Cl: 1.44-1.90).

Table 2 shows the gender, age, level of education and anatomical region with the most severe injury, classified according to the type of safety gear that was used. The (anatomical) areas with the highest incidence of injuries are those classified as multiple $(21.76 \%)$, head and face $(23.15 \%)$, lower limbs (20.90\%) and upper limbs (13.60\%), unlike injuries that caused death (Table 3 ), where $55.1 \%$ of deaths are attributed to intracranial trauma. Overall, $13.73 \%$ were under the influence of alcohol, with 1.89-fold higher probability of fatal accident (95\% Cl: $1.46-2.44) ; 0.30 \%$ were under the influence of illegal drugs; $0.17 \%$ consumed medical drugs; $16.6 \%$ of injured subjects wore a helmet or another safety gear; and only $9.7 \%$ with head injuries wore a helmet. Thus, people not wearing a helmet were found to have 2.11 -fold $(95 \% \mathrm{Cl}$ : 1.82-2.44) higher probabilities to suffer a head injury.

\section{Discussion}

Motorcyclists are well known to be a group that is particularly vulnerable on the road. Some studies indicate that the risk for suffering motorcycle injuries is between 10 and 30 -fold higher than that of automobile drivers $^{5,9}$. This is not only owing to the shape of the vehicle, which keeps the body at open sky and limits, in comparison with automobiles, passive safety system options (such as safety belt or the cabin of the vehicle itself), but, in addition to the lack of crash protection, motorcyclists are at risk of not being seen by other automobile drivers and impact with security barriers that have been designed for other type of vehicles.

In Mexico, INEGI data indicate that motorcycles contribute with $5.97 \%$ of total circulating registered motor vehicles, are involved in $5.84 \%$ of crashes and are involved in $13.14 \%$ of ground traffic collision deadly victims. However, the number of automobiles is 11.25fold higher than that of motorcycles, and comparisons in absolute terms underestimate the seriousness of collisions and the vulnerability of certain groups (which are better appreciated in relative terms), since both the number of vehicles and travels and kilometers render accident figures not being directly comparable. Notwithstanding, motorcycle accidents have a 1:10.78 ratio in comparison with automobile accidents, and this 
Gaceta Médica de México. 2017;153

Table 1. Motorcycle accidents according to their class

\begin{tabular}{|c|c|c|c|c|c|c|c|c|}
\hline \multirow[t]{2}{*}{ Characteristic } & \multicolumn{2}{|c|}{ Fatal } & \multicolumn{2}{|c|}{ Non-fatal } & \multicolumn{2}{|c|}{ Only damages } & \multirow[b]{2}{*}{$\stackrel{\infty}{-}$} & \multirow[t]{2}{*}{$p$} \\
\hline & \multicolumn{2}{|c|}{$N=826$} & \multicolumn{2}{|c|}{$N=23,954$} & \multicolumn{2}{|c|}{$\mathrm{N}=17,101$} & & \\
\hline \multicolumn{7}{|l|}{ Driver gender } & $\stackrel{\sim}{\simeq}$ & \\
\hline Ran away & 162 & $(19.6 \%)$ & 2,995 & $(12.5 \%)$ & 1,722 & $(10.1 \%)$ & $\geq$ & $<0.001$ \\
\hline Male & 628 & $(76 \%)$ & 18,401 & $(76.8 \%)$ & 13,647 & $(79.8 \%)$ & $\frac{c}{\sigma}$ & \\
\hline Female & 36 & $(4.4 \%)$ & 2,558 & $(10.7 \%)$ & 1,732 & $(10.1 \%)$ & $\underline{E}$ & \\
\hline \multicolumn{7}{|l|}{ Cause of accident } & $\frac{1}{2}$ & \\
\hline Driver & 804 & $(97.3 \%)$ & 22,788 & $(95.1 \%)$ & 16,397 & $(95.9 \%)$ & (3) $<$ & $<0.001$ \\
\hline Pedestrian or passenger & 9 & $(1.1 \%)$ & 390 & $(1.6 \%)$ & 21 & $(0.1 \%)$ & & \\
\hline Vehicle malfunction & 4 & $(0.5 \%)$ & 90 & $(0.4 \%)$ & 64 & $(0.4 \%)$ & $\frac{\dot{\alpha}}{\alpha}$ & \\
\hline Road bad condition & 4 & $(0.5 \%)$ & 359 & $(1.5 \%)$ & 396 & $(2.3 \%)$ & $\frac{\sigma}{n}$ & \\
\hline Other & 5 & $(0.6 \%)$ & 327 & $(1.4 \%)$ & 223 & $(1.3 \%)$ & 으 & \\
\hline \multicolumn{7}{|l|}{ Road surface } & 임 & \\
\hline Paved & 779 & $(94.3 \%)$ & 23,527 & $(98.2 \%)$ & 16,937 & $(99 \%)$ & $<$ & $<0.001$ \\
\hline Unpaved & 47 & $(5.7 \%)$ & 427 & $(1.8 \%)$ & 164 & $(1 \%)$ & 4 & \\
\hline \multicolumn{7}{|l|}{ Area where the accident } & $\frac{c}{\circ}<$ & \\
\hline Urban & 340 & $(41.2 \%)$ & 2,302 & $(9.6 \%)$ & 811 & $\begin{array}{l}(90.0 \%) \\
(4.7 \%)\end{array}$ & $\frac{N}{E}$ & \\
\hline Suburban & & & & & & & $\frac{5}{2}$ & \\
\hline \multicolumn{7}{|l|}{ Breath alcohol conditions } & $\frac{\varsigma}{d}$ & \\
\hline Yes & 74 & $(9 \%)$ & 1,744 & $(7.3 \%)$ & 737 & $(4.3 \%)$ & $\pm<$ & $<0.001$ \\
\hline No & 338 & $(40.9 \%)$ & 14,920 & $(62.3 \%)$ & 10,247 & $(59.9 \%)$ & 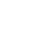 & \\
\hline Not known & 414 & $(50.1 \%)$ & 7,290 & $(30.4 \%)$ & 6,117 & $(35.8 \%)$ & 힌 & \\
\hline \multicolumn{7}{|l|}{ Injured person age } & 흐 & \\
\hline $0-20$ years & 132 & $(16 \%)$ & 3768 & $(15.7 \%)$ & 2701 & $(15.8 \%)$ & $\stackrel{c}{c}<$ & $<0.001$ \\
\hline $21-30$ years & 223 & $(27 \%)$ & 6530 & $(27.3 \%)$ & 4724 & $(27.6 \%)$ & \pm & \\
\hline $31-40$ years & 111 & $(13.4 \%)$ & 4314 & $(18 \%)$ & 3253 & $(19 \%)$ & $\stackrel{5}{3}$ & \\
\hline $41-50$ years & 70 & $(8.5 \%)$ & 2653 & $(11.1 \%)$ & 1955 & $(11.4 \%)$ & 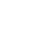 & \\
\hline $51-60$ years & 35 & $(4.2 \%)$ & 1439 & $(6 \%)$ & 1039 & $(6.1 \%)$ & $\overline{3}$ & \\
\hline $61-90$ years & 11 & $(1.3 \%)$ & 932 & $(3.9 \%)$ & 576 & $(3.4 \%)$ & 이 & \\
\hline Not specified & 82 & $(9.9 \%)$ & 1,323 & $(5.5 \%)$ & 1,131 & $(6.6 \%)$ & $\stackrel{\subsetneq}{\searrow}$ & \\
\hline Driver ran away & 162 & $(19.6 \%)$ & 2995 & $(12.5 \%)$ & 1722 & $(10.1 \%)$ & $\frac{2}{2}$ & \\
\hline \multicolumn{7}{|l|}{ Day of the week } & 웅 & \\
\hline Monday & 108 & $(13.1 \%)$ & 3,359 & $(14 \%)$ & 2,407 & $(14.1 \%)$ & $-<$ & $<0.001$ \\
\hline Tuesday & 74 & $(9 \%)$ & 3,077 & $(12.8 \%)$ & 2,312 & $(13.5 \%)$ & 党 & \\
\hline Wednesday & 92 & $(11.1 \%)$ & 3,181 & $(13.3 \%)$ & 2,422 & $(14.2 \%)$ & $\circ$ & \\
\hline Thursday & 98 & $(11.9 \%)$ & 3,027 & $(12.6 \%)$ & 2,368 & $(13.8 \%)$ & d & \\
\hline Friday & 88 & $(10.7 \%)$ & 3,560 & $(14.9 \%)$ & 2,719 & $(15.9 \%)$ & $\frac{u}{3}$ & \\
\hline Saturday & 172 & $(20.8 \%)$ & 4,113 & $(17.2 \%)$ & 2,709 & $(15.8 \%)$ & 욤 & \\
\hline Sunday & 194 & $(23.5 \%)$ & 3,637 & $(15.2 \%)$ & 2,164 & $(12.7 \%)$ & $\frac{\partial}{0}$ & \\
\hline \multicolumn{7}{|l|}{ Type of accident } & 8 & \\
\hline Collision with vehicle & 48 & $(5.8 \%)$ & 1,562 & $(6.5 \%)$ & 0 & $(0 \%)$ & $><$ & $<0.001$ \\
\hline Collision with pedestrian & 29 & $(3.5 \%)$ & 1,535 & $(6.4 \%)$ & 30 & $(0.2 \%)$ & $\stackrel{\sigma}{E}$ & \\
\hline Collision with animal & 11 & $(1.3 \%)$ & 107 & $(0.4 \%)$ & 522 & $(3.1 \%)$ & 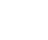 & \\
\hline Collision with fixed object & 119 & $(14.4 \%)$ & 838 & $(3.5 \%)$ & 200 & $(1.2 \%)$ & $\stackrel{\circ}{-}$ & \\
\hline Rollover & 51 & $(6.2 \%)$ & 851 & $(3.6 \%)$ & 0 & $(0 \%)$ & $\overrightarrow{0}$ & \\
\hline Passenger fall & 14 & $(1.7 \%)$ & 599 & $(2.5 \%)$ & 162 & $(0.9 \%)$ & 응 & \\
\hline Roadway departure & 59 & $(7.1 \%)$ & 456 & $(1.9 \%)$ & 4 & $(0 \%)$ & $\frac{0}{5}$ & \\
\hline Fire & 0 & $(0 \%)$ & 7 & $(0 \%)$ & 4 & $(0 \%)$ & $\frac{2}{n}$ & \\
\hline Collision with train & 1 & $(0.1 \%)$ & 4 & $(0 \%)$ & 14,558 & $(85.1 \%)$ & 至 & \\
\hline Collision with motorcycle & 461 & $(55.8 \%)$ & 16,864 & $(70.4 \%)$ & 128 & $(0.7 \%)$ & + & \\
\hline Collision with cyclist & 12 & $(1.5 \%)$ & 369 & $(1.5 \%)$ & 281 & $(1.6 \%)$ & $\circ$ & \\
\hline Other & 21 & $(2.5 \%)$ & 765 & $(3.2 \%)$ & 0 & $(0 \%)$ & $\frac{\pi}{0}$ & \\
\hline
\end{tabular}

proportion changes to 1:0.96 when, instead of the population, the ratio of accidents is considered per number of vehicles, and to 1:3.5 when only fatal accidents are taken into account. However, the number of motorcycles has a more accelerated growth, which positively correlates with the number of accidents $(R=0.93$; $p<$ data 
Table 2. Injured motorcyclists characteristics according to the type of safety gear

\begin{tabular}{|c|c|c|c|c|c|c|c|c|}
\hline \multirow[t]{3}{*}{ Characteristic } & \multicolumn{8}{|c|}{ Type of safety gear } \\
\hline & \multicolumn{2}{|c|}{ Helmet } & \multicolumn{2}{|c|}{ Other gear } & \multicolumn{2}{|c|}{ No gear } & \multicolumn{2}{|c|}{ Subtotal } \\
\hline & $N=2310$ & $(100 \%)$ & $N=194$ & $(100 \%)$ & $N=11412$ & $(100 \%)$ & $N=13916$ & $(100 \%)$ \\
\hline \multicolumn{9}{|c|}{ Injured person gender } \\
\hline Male & 1813 & $(78.5 \%)$ & 145 & $(74.7 \%)$ & 8,701 & $(76.2 \%)$ & 10,661 & $(76.6 \%)$ \\
\hline Female & 497 & $(21.5 \%)$ & 49 & $(25.3 \%)$ & 2,710 & $(23.7 \%)$ & 3,256 & $(23.4 \%)$ \\
\hline Not specified & 0 & $(0.0 \%)$ & 0 & $(0.0 \%)$ & 1 & $(0.0 \%)$ & 1 & $(0.0 \%)$ \\
\hline \multicolumn{9}{|l|}{ Level of education } \\
\hline Primary & 521 & $(22.6 \%)$ & 57 & $(29.4 \%)$ & 2910 & $(25.5 \%)$ & 3489 & (25.1\%) \\
\hline Secondary & 885 & $(38.3 \%)$ & 55 & (28.4\%) & 3929 & $(34.4 \%)$ & 4870 & $(35.0 \%)$ \\
\hline High school & 547 & $(23.7 \%)$ & 42 & $(21.6 \%)$ & 2164 & $(19.0 \%)$ & 2753 & $(19.8 \%)$ \\
\hline Higher education & 151 & $(6.5 \%)$ & 16 & $(8.2 \%)$ & 486 & $(4.3 \%)$ & 653 & $(4.7 \%)$ \\
\hline Other & 92 & $(4.0 \%)$ & 15 & $(7.7 \%)$ & 567 & $(5.0 \%)$ & 674 & $(4.8 \%)$ \\
\hline None & 86 & (3.7\%) & 6 & $(3.1 \%)$ & 674 & $(5.9 \%)$ & 766 & $(5.5 \%)$ \\
\hline Not specified & 28 & $(1.2 \%)$ & 3 & $(1.5 \%)$ & 682 & $(6.0 \%)$ & 713 & $(5.1 \%)$ \\
\hline \multicolumn{9}{|l|}{ Age } \\
\hline $0-20$ years & 686 & $(29.7 \%)$ & 54 & $(27.8 \%)$ & 4249 & $(37.2 \%)$ & 4989 & $(35.9 \%)$ \\
\hline $21-30$ years & 893 & (38.7\%) & 64 & $(33.0 \%)$ & 4089 & (35.8\%) & 5046 & $(36.3 \%)$ \\
\hline $31-40$ years & 396 & (17.1\%) & 46 & (23.7\%) & 1651 & $(14.5 \%)$ & 2093 & (15.0\%) \\
\hline $41-50$ years & 214 & $(9.3 \%)$ & 18 & $(9.3 \%)$ & 858 & $(7.5 \%)$ & 1090 & $(7.8 \%)$ \\
\hline $51-60$ years & 94 & $(4.1 \%)$ & 5 & $(2.6 \%)$ & 359 & $(3.1 \%)$ & 458 & $(3.3 \%)$ \\
\hline $60-99$ years & 26 & $(1.1 \%)$ & 7 & $(3.6 \%)$ & 199 & $(1.7 \%)$ & 232 & $=(1.7 \%)$ \\
\hline Not specified & 1 & $(0.0 \%)$ & 0 & $(0.0 \%)$ & 7 & $(0.1 \%)$ & 8 & $3(0.1 \%)$ \\
\hline \multicolumn{9}{|c|}{ Most seriously injured anatomical area } \\
\hline Head & 224 & $(9.7 \%)$ & 42 & $(21.6 \%)$ & 2107 & $(18.5 \%)$ & 2373 & (17.1\%) \\
\hline Face & 115 & $(5.0 \%)$ & 10 & $(5.2 \%)$ & 723 & $(6.3 \%)$ & 848 & $(6.1 \%)$ \\
\hline Ocular region & 3 & $(0.1 \%)$ & 0 & $(0.0 \%)$ & 26 & $(0.2 \%)$ & 29 & $=(0.2 \%)$ \\
\hline Neck & 49 & $(2.1 \%)$ & 11 & $(5.7 \%)$ & 214 & $(1.9 \%)$ & 274 & $(2.0 \%)$ \\
\hline Vertebral column & 16 & $(0.7 \%)$ & 0 & $(0.0 \%)$ & 79 & $(0.7 \%)$ & 95 & $(0.7 \%)$ \\
\hline Upper limbs & 344 & $(14.9 \%)$ & 21 & $(10.8 \%)$ & 1527 & $(13.4 \%)$ & 1892 & $(13.6 \%)$ \\
\hline Hand & 89 & $(3.9 \%)$ & 6 & $(3.1 \%)$ & 479 & $(4.2 \%)$ & 574 & $(4.1 \%)$ \\
\hline Chest & 71 & $(3.1 \%)$ & 13 & $(6.7 \%)$ & 354 & $(3.1 \%)$ & 438 & $(3.1 \%)$ \\
\hline Back or glutei & 21 & $(0.9 \%)$ & 5 & $(2.6 \%)$ & 89 & $(0.8 \%)$ & 115 & $(0.8 \%)$ \\
\hline Abdomen & 14 & $(0.6 \%)$ & 3 & $(1.5 \%)$ & 90 & $(0.8 \%)$ & 107 & $(0.8 \%)$ \\
\hline Pelvis & 23 & $(1.0 \%)$ & 1 & $(0.5 \%)$ & 87 & $(0.8 \%)$ & 111 & $(0.8 \%)$ \\
\hline Genital region & 3 & $(0.1 \%)$ & 1 & $(0.5 \%)$ & 16 & $(0.1 \%)$ & 20 & $(0.1 \%)$ \\
\hline Lower limbs & 600 & $(26.0 \%)$ & 34 & $(17.5 \%)$ & 2274 & (19.9\%) & 2908 & $(20.9 \%)$ \\
\hline Feet & 101 & $(4.4 \%)$ & 5 & $(2.6 \%)$ & 388 & $(3.4 \%)$ & 494 & $(3.6 \%)$ \\
\hline Multiple & 577 & $(25.0 \%)$ & 33 & $(17.0 \%)$ & 2418 & $(21.2 \%)$ & 3028 & $(21.8 \%)$ \\
\hline Other & 54 & $(2.3 \%)$ & 6 & $(3.1 \%)$ & 439 & $(3.8 \%)$ & 499 & $(3.6 \%)$ \\
\hline Not known & 6 & $(0.3 \%)$ & 3 & $(1.5 \%)$ & 102 & $(0.9 \%)$ & 111 & $(0.8 \%)$ \\
\hline
\end{tabular}

from other cities of the world, where motorcyclists' mortality has increased up to $875 \%{ }^{10}$. On the other hand, it can be inferred that the different proportions and atypical numbers of both motorcycles and accidents in different regions of the country are the consequence of disparities in the degree of industrialization, the population level, the motorization rate and the rapid growth of auto rickshaws as means of transportation ${ }^{11}$.

With regard to the injured part of the body, as in other places of the world ${ }^{12-15}$, the head is the most important; even injuries classified as multiple injuries are composed to a large extent of head injuries and intracranial traumas. In spite of legislative efforts to regulate the use of helmet, Mexican culture plays an important role in injuries. Paradoxically, it is common to observe that the helmet is used only to comply with traffic regulations, and it is used in inadequate size or manner; for example, children wearing adult helmets or people carrying the helmet in the arm. The intention is avoiding sanctions and not to be protected against injuries. In Mexico City's most recent traffic code ${ }^{16}$, which is presumably one of the most advanced in the country and that came into force in December 2015, article 27 already states that the helmet shall be worn on the head; however, neither the use nor the 
Gaceta Médica de México. 2017;153

Table 3. Causes of morbidity and mortality in motorcyclists, classified by type of hospital discharge

\begin{tabular}{|c|c|c|c|c|c|c|}
\hline \multirow[t]{2}{*}{ Cause of morbidity and mortality } & \multicolumn{2}{|c|}{ Other discharges } & \multicolumn{2}{|c|}{ Deaths } & \multicolumn{2}{|c|}{ Subtotal } \\
\hline & $N=9,111$ & $(100 \%)$ & $N=225$ & $(100 \%)$ & $N=9,336$ & $(100 \%)$ \\
\hline Intracranial trauma & 1,199 & $(13.2 \%)$ & 124 & $(55.1 \%)$ & 1,323 & $(14.2 \%)$ \\
\hline Other traumas & 1,879 & $(20.6 \%)$ & 71 & $(31.6 \%)$ & 1,950 & $(20.9 \%)$ \\
\hline Skull and facial bones fracture & 380 & $(4.2 \%)$ & 4 & $(1.8 \%)$ & 384 & $(4.1 \%)$ \\
\hline Other fractures & 483 & $(5.3 \%)$ & 4 & $(1.8 \%)$ & 487 & $(5.2 \%)$ \\
\hline Fracture of the leg, including the ankle & 2,114 & $(23.2 \%)$ & 3 & $(1.3 \%)$ & 2,117 & $(22.7 \%)$ \\
\hline Upper and lower limb amputations & 56 & $(0.6 \%)$ & 3 & $(1.3 \%)$ & 59 & $(0.6 \%)$ \\
\hline Femoral fracture & 770 & $(8.5 \%)$ & 2 & $(0.9 \%)$ & 772 & $(8.3 \%)$ \\
\hline Upper and lower limb injuries & 235 & $(2.6 \%)$ & 1 & $(0.4 \%)$ & 236 & $(2.5 \%)$ \\
\hline Fractures of the vertebral column (cervical, dorsal and lumbar) & 46 & $(0.5 \%)$ & 1 & $(0.4 \%)$ & 47 & $(0.5 \%)$ \\
\hline Fractures of the shoulder, arm and forearm & 1,096 & $(12.0 \%)$ & 1 & $(0.4 \%)$ & 1,097 & $(11.8 \%)$ \\
\hline Injury of the chest, abdomen, lumbosacral region and pelvis & 29 & $(0.3 \%)$ & 1 & $(0.4 \%)$ & 30 & $(0.3 \%)$ \\
\hline Burns and corrosions & 13 & $(0.1 \%)$ & 1 & $(0.4 \%)$ & 14 & $(0.1 \%)$ \\
\hline Fracture of the wrist and hand & 193 & $(2.1 \%)$ & 0 & $(0.0 \%)$ & 193 & $(2.1 \%)$ \\
\hline Dislocations, sprains and tears of multiple regions & 333 & $(3.7 \%)$ & 0 & $(0.0 \%)$ & 333 & $(3.6 \%)$ \\
\hline Head injury & 117 & $(1.3 \%)$ & 0 & $(0.0 \%)$ & 117 & $(1.3 \%)$ \\
\hline Other injuries & 58 & $(0.6 \%)$ & 0 & $(0.0 \%)$ & 58 & $(0.6 \%)$ \\
\hline Other causes & 107 & $(1.2 \%)$ & 8 & $(3.6 \%)$ & 115 & $(1.2 \%)$ \\
\hline III-defined causes & 3 & $(0.0 \%)$ & 1 & $(0.4 \%)$ & 4 & $(0.0 \%)$ \\
\hline
\end{tabular}

commercialization of helmets are regulated, and seeing very cheap but inadequate helmets that don't meet safety standards is therefore usual. However, creating regulations that mandate the use of safe helmets, homologated with international standards, is a controversial topic, mainly because helmets that meet these standards, such as Semell and DOT in the USA and ECE/ONU R22 in Europe, are twice or thrice more expensive ${ }^{17}$. If jackets, gloves, boots and other protective gear are added, the safety gear turns out being more expensive than a scooter or one of the low-cylinder capacity motorcycles that are commercialized in Mexico. Protective gear increases the costs of motorcycles and discourages the use of this means of transportation, which has emerged to replace the mobility needs in cities with public transportation systems that are uncomfortable and unattractive for users. This represents a serious problem owing to the low purchasing power of the population and, although safety should not be negotiable, regulations on the use and commercialization of helmets are unpopular measures, with political costs legislators resist to assume.
In the case of Mexico, since sensitization campaigns have yielded poorly effective results, legislation and strict mechanisms to enforce its obedience should be strengthened, since, in spite of traffic regulations in some cities having included the mandatory use of helmet for more than a decade, the results indicate that $83.99 \%$ of injured individuals didn't wear any type of helmet, and this risky behavior exposes motorcyclists to 2.11 -fold (95\% Cl: $1.82-2.44)$ higher probabilities to suffer head injuries with regard to those who do wear helmet. These results are consistent with those of other studies that indicate that motorcyclists wearing helmet, even of any type ${ }^{18}$, have a significantly lower number of head and neck injuries, at all levels of seriousness and for all types of injuries $^{19}$. Motorcyclists who wear helmet have been shown to reduce by $25 \%$ the probability of being injured and by $30 \%$ if other protective gear (such as leather clothes) is used and, in combination with the entire gear, risks are therefore reduced by nearly $50 \%$.

The prevalence of the use of helmet varies around the world; for example, the literature shows values in 
emerging countries of $16.2 \%$ in Laos ${ }^{20}, 40 \%$ in Argentina $^{21}, 48 \%$ in Cambodia ${ }^{22}$ and $88.7 \%$ in Malaysia ${ }^{23}$. The variations are due to cultural, socioeconomic, environmental, temporal and regulatory factors that are particular to each region ${ }^{24-27}$. For Mexican cities, the recorded prevalence values are $68.9 \%$ in León, $62.7 \%$ in Guadalajara and $71.55 \%$ in Cuernavaca, with an average of $73.8 \%$ in these cities ${ }^{28}$. Nevertheless, in addition to the results being nation-wide total and not of a series of cities, the figure for the prevalence of helmet use in injured subjects is lower (16.59 vs. $73.8 \% ; p<0.001$; this is due to the fact that the comparison study does not include injured individuals, but only circulating motorcyclists, and the obtained data are on total injured population and not on motorcyclists. The sample may be biased because injured individuals can take on higher risks than motorcyclists that haven't had accidents. However, there are data ${ }^{29}$ indicating that, when the proportions are compared, there appears to be no difference; for example, among those who wear a helmet, the majority are drivers (83.29\%) and the rest are passengers (16.71\%). In the comparison study, this variable is recorded at $84 \%$ and, therefore, when the hypothesis testing for the difference of proportions is made, the fact of them being equal cannot be rejected $(83.29 \%$ vs. $84 \%$; $p=$ 0.520).

With regard to the use of helmet among the injured subjects, in a study conducted in German motorcyclists $^{30}, 72.5 \%$ were reported not to wear helmet, which is a closer figure to the $83.3 \%$ of our results. However, the study shows that motorcyclists suffered head injuries at a rate of $70 \%$ for those who didn't wear a helmet and $45 \%$ for those who did, unlike our results, where rates of 18.52 and $9.70 \%$, respectively, were obtained.

On the other hand, other factors observed in injured subjects are those referring to the road and the geographic zone, where in spite of $98.48 \%$ of collisions occurring on paved surfaces, a fatal accident is 3.3fold (95\% Cl: $2.43-4.5)$ more likely to occur in unpaved surfaces and 6.5-fold (95\% Cl: 5.69-7.60) more probable in suburban areas.

With regard to the type of accident, $50 \%$ of motorcycle accident victims were found to involve the collision with an automobile, a van or other transportation accidents, and $42.93 \%$ were found to be accidents without a collision. These proportions are similar to those found in other countries ${ }^{31}$, where around $60 \%$ of injured individuals and $40 \%$ motorcycle-associated deaths involve collision with an automobile and around
$20 \%$ of injured subjects and $25 \%$ of fatal victims are related to single-vehicle collisions.

On the other hand, the days with higher risk are Saturdays and Sundays with 1.65-fold $(95 \% \mathrm{Cl}$ : 1.44-1.90) higher probabilities of accidents than the rest of the week. This weekend peak is known to be due to recreational rides ${ }^{31}$, especially in motorcycles with engines of more than 500 cubic centimeters, and although in Mexico this information is not available, it can be inferred that it behaves similarly, since the use of working motorcycles, which generally have smaller cylinder capacity, is decreased on weekends.

While alcohol consumption increases the risk by 1.89-fold (95\% Cl: 1.46-2.44) in responsible drivers, the majority $(78.02 \%)$ belong to the male gender, with 2.4 -fold (95\% Cl: $1.70-3.31)$ higher probability. This supports the belief that women have lower rates of participation in accidents, particularly among young drivers. Such gender differences have been found in collision analyses of numerous investigations on motorcyclists ${ }^{23,32}$. However, the $13.73 \%$ alcohol consumption prevalence is much lower than those found in other studies ${ }^{33}$, which indicate that between 41 and $80 \%$ of injured motorcycle drivers tested positive for alcohol consumption. This may be due to underreporting in the information, but the subject should be further investigated.

Finally, despite the importance of the results, it is necessary to consider that some variables of interest were not included in this study owing to the lack of information; for example, the INEGI database does not record safety gear or anatomical region of injuries and there is also large underreporting of data, and none of the analyzed databases match in their figures, which may be due to the fact that the violence or injury-related care form (SIS-SS-17-P) does not include motorcycles as an agent of injury. Another important factor is that, during the construction of indicators, the injured and fatal victim rates do not consider motorcyclists or vehicles with several collisions. Despite the information limitations, the results of this study constitute an approach to the problem of motorcyclists in Mexico and the variables that have to be considered in the development of programs of actions to prevent injuries. Mexico has advanced in terms of road safety; at least, it has been acknowledged as a health problem since several years ago, and initiatives, organizations and agreements have been established in order to fight this problem. Non-use of helmet was one of the six risk factors included in the Mexican Initiative 
for Road Safety program, and the use of helmet has been gradually reinforced in traffic regulation; in addition, standards for helmet commercialization are already being planned.

There is much left to do in order to achieve a reduction in motorcyclists' injuries, and it is therefore important for good road practices to be fostered, for protective factors and use of safety gear to be promoted in order to increase the percentage of people using helmet and protective gear, for road infrastructure to be adapted to this type of vehicles, and for drivers and passengers to be made aware about the risks of using a motorcycle, for example, for recreational use, on weekends and under the influence of alcohol.

\section{References}

1. WHO. Helmets: a road safety manual for decision-makers and practitioners. Geneva: World Health Organization; 2006.

2. Huang B, Preston J. A literature review on motorcycle collisions: final report. Oxford, England: University of Oxford; 2004

3. Chesham DJ, Rutter DR, Quine L. Motorcycling safety research: a review of the social and behavioural literature. Soc Sci Med. 1993;37:419-29.

4. Mannering FL, Grodsky LL. Statistical analysis of motorcyclists' perceived accident risk. Accid Anal Prev. 1995;27:21-31.

5. Bjornskau T, Naevestad T-O, Akhtar J. Traffic safety among motorcyclists in Norway: a study of subgroups and risk factors. Accid Anal Prev.2011;49:50-7.

6. INEGI. Vehículos de motor registrados en circulación, 2014. (Accedido el 21 de julio de 2016.) Disponible en: http://www.inegi.org.mx/est/contenidos/proyectos/registros/economicas/vehiculos.

7. INEGI. Accidentes de tránsito terrestre en zonas urbanas y suburbanas 2014. (Accedido el 21 de julio de 2016.) Disponible en: http://www.inegi. org.mx/est/contenidos/proyectos/registros/economicas/accidentes.

8. Dirección General de Información en Salud. Sistema Nacional de Información en Salud: Lesiones, 2014.(Accedido el 21 de julio de 2016.) Disponible en: http://www.dgis.salud.gob.mx/contenidos/sinais/estadisticas.html.

9. Elvik R, Vaa T, Monclús J. El manual de medidas de seguridad vial. España: Fundación Instituto Tecnológico para Seguridad del Automóvil 2006.

10. Silva PHNdV, Lima MLC, Souza WV, et al. Muertes por accidente de motocicleta y su asociación con variables relacionadas a la reproducción social en un estado del noreste brasileño. Salud Colectiva.2015;11:401.

11. Berrones Sanz LD. The working conditions of motorcycle taxi drivers in Tláhvac, Mexico City. Journal of Transport and Health, 2017.

12. Yusuf A, Adeleke N, Adeniran J, et al. Pattern and outcome of motorcyclists head injury in Ilorin, Nigeria. Niger J Basic Clin Sci.2014;11:80.
13. Tosi JD, Ledesma RD, Poó FM, et al. Prevalencia y evolución del uso de casco en ocupantes de motocicletas en una ciudad argentina (Mar del Plata, 2006-2014). SC.2016;12:85.

14. Yu W-Y, Chen C-Y, Chiu W-T, et al. Effectiveness of different types of motorcycle helmets and effects of their improper use on head injuries. Int J Epidemiol. 2011;40:794-803.

15. Oxley J, Ravi MD, Yuen J, et al. Identifying contributing factors to fatal and serious injury motorcycle collisions involving children in Malaysia. Ann Adv Automot Med. 2013;57:329-36.

16. Reglamento de Tránsito del Distrito Federal. Gaceta Oficial del Distrito Federal.2015; 3-122.

17. Ackaah W, Afukaar F, Agyemang W, et al. The use of non-standard motorcycle helmets in low- and middle-income countries: a multicentre study. Inj Prev.2013;19:158-63.

18. Peek-Asa C, McArthur DL, Kraus JF. The prevalence of non-standard helmet use and head injuries among motorcycle riders. Accid Anal Prev. 1999;31:229-33.

19. Hurt HH, Ouellet JV, Thom DR. Motorcycle accident cause factors and identification of countermeasures: volume I: final report.Washington, D.C., Springfield, Va.: National Highway Traffic Safety Administration; 1981.

20. Fong MC, Measelle JR, Dwyer JL, et al. Rates of motorcycle helmet use and reasons for non-use among adults and children in Luang Prabang, Lao People's Democratic Republic. BMC Public Health.2015;15:970.

21. Ledesma RD, Peltzer RI. Helmet use among motorcyclists: observational study in the city of Mar del Plata, Argentina. Rev Saúde Pública 2008:42:143-5.

22. Bachani AM, Branching C, Ear C, et al. Trends in prevalence, knowledge, attitudes, and practices of helmet use in Cambodia: results from a two year study. Injury. 2013:44:S31-7.

23. Ramli R, Oxley J, Hillard $P$, et al. The effect of motorcycle helmet type, components and fixation status on facial injury in Klang Valley, Malaysia: a case control study. BMC Emerg Med. 2014;14:17.

24. Xuequn $\mathrm{Y}, \mathrm{Ke} \mathrm{L}$, Ivers $\mathrm{R}$, et al. Prevalence rates of helmet use among motorcycle riders in a developed region in China. Accid Anal Prev. 2011;43:214-9.

25. Zamani-Alavijeh $F$, Bazargan $M$, Shafiei $A$, et al. The frequency and predictors of helmet use among Iranian motorcyclists: aquantitative and qualitative study. Accid Anal Prev. 2011;43:1562-9.

26. Akaateba MA, Amoh-Gyimah R, Yakubu I. A cross-sectional observational study of helmet use among motorcyclists in Wa, Ghana. Accid Anal Prev. 2014;64:18-22.

27. Nicholson SL, Donaghy M, Johnston M, et al. A qualitative theory guided analysis of stroke survivors' perceived barriers and facilitators to physical activity. Disabil Rehabil. 2014;36:1857-68.

28. Lunnen JC, Pérez-Núñez R, Hidalgo-Solórzano E, et al. The prevalence of motorcycle helmet use from serial observations in three Mexican cities. Int J Inj Contr Saf Promot.2014;22:368-76.

29. Hidalgo-Solorzano E, Inclán-Valadez C, Pérez-Núñez R, et al. Motorcycle non-standard helmet use in an urban area of Mexico. Inj Prevent.2012;18:A192.

30. Otte $D$, JessI $P$, Suren EG. Impact points and resultant injuries to the head of motorcyclists involved in accidents, with and without crash helmets. Proceedings of the 1984 International Conference on the Biomechanics of Impacts. The Netherlands, 4-6th 1984.

31. Elliott MA, Baughan CJ, Broughton J, et al. Motorcycle safety: a scoping study.Transport Research Laboratory; 2003.

32. Mannering FL. Male/female driver characteristics and accident risk: some new evidence. Accid Anal Prev. 1993;25:77-84.

33. Preusser DF, Williams AF, Ulmer RG. Analysis of fatal motorcycle crashes: crash typing. Accid Anal Prev. 1995;27:845-51. 